\title{
Antithrombotic therapy in elderly patients with non-valvular atrial fibrillation: a pilot study
}

This article was published in the following Dove Press journal:

Clinical Interventions in Aging

2 March 2015

Number of times this article has been viewed

\section{Wei Xiang \\ Jingwei Zhang \\ Meilin Liu \\ Fang Liu \\ Xueru Feng \\ Yuchuan Wang}

Department of Geriatrics, Peking University First Hospital, Beijing,

People's Republic of China
Correspondence: Meilin Liu

Department of Geriatrics, Peking University First Hospital, Xi Shi Ku Street No 7, Xicheng District, Beijing 100034,

People's Republic of China

Tel +86 1083572022

Fax +86106 6552095

Email meilinliu@yahoo.com
Objective: Non-valvular atrial fibrillation (NVAF) is one common arrhythmia in the elderly. However, use of antithrombotic therapy in this population is not well known in the People's Republic of China. This study aimed at investigating antithrombotic therapy status in elderly patients with NVAF in our hospital.

Methods: A cross-sectional study of consecutive geriatric patients aged $\geq 60$ years with NVAF who discharged from our hospital between January 2012 and December 2013 were collected. $\mathrm{CHA}_{2} \mathrm{DS}_{2}-\mathrm{VASc}$ score (cardiac failure or dysfunction, hypertension, age $\geq 75$ [doubled], diabetes, stroke or transient ischemic attack [doubled], vascular disease, age 65-74, and sex category [female]) was used to analyze antithrombotic indication.

Results: We consecutively collected data of 1,000 discharged elderly patients ( $\geq 60$ years) with NVAF (mean age $75.3 \pm 8.0$ years, 75 years or older $54.7 \%$, female $42.7 \%$ ). The proportion of paroxysmal atrial fibrillation and non-paroxysmal atrial fibrillation (persistent or permanent) patients were $39.4 \%$ and $60.6 \%$, respectively. Among 1,000 patients, $29.1 \%$ received oral anticoagulant therapy (OAT), including warfarin (27.8\%) and novel oral anticoagulants $(1.3 \%)$, $39.5 \%$ of patients received antiplatelet therapy, and $31.4 \%$ received neither therapy. Based on $\mathrm{CHA}_{2} \mathrm{DS}_{2}$-VASc score for stroke risk stratification, $68.9 \%$ patients with score $\geq 1$ and $70.2 \%$ patients with score $\geq 2$ received antithrombotic therapy, while the rates of OAT were $29.1 \%$ and $29.5 \%$, respectively. Among patients with high stroke risk, those with paroxysmal atrial fibrillation were less likely to receive OAT compared with the patients with non-paroxysmal atrial fibrillation ( $19.5 \%$ vs $35.7 \%, P<0.001)$. The patients $\geq 75$ years old had lower rate of OAT than the patients $<75$ years old $(25.8 \%$ vs $34.8 \%, P=0.003)$. The patients with coronary artery disease had lower rate of OAT than the patients without coronary artery disease $(24.4 \%$ vs $33.4 \%, P=0.003)$. Sex and history of stroke or transient ischemic attack had no effect on the use of OAT ( $30.8 \%$ vs $27.9 \%, P=0.326$ and $28.8 \%$ vs $29.8 \%, P=0.761$, respectively) .

Conclusion: OAT in elderly patients with NVAF in our hospital is underused, especially in those patients with higher risk of stroke.

Keywords: elderly, atrial fibrillation, ischemic stroke, anticoagulation, $\mathrm{CHA}_{2} \mathrm{DS}_{2}-\mathrm{VASc}$ score

\section{Introduction}

Non-valvular atrial fibrillation (NVAF) is a very common arrhythmia, and its prevalence increases significantly with age. ${ }^{1,2}$ According to epidemic data, the prevalence of atrial fibrillation (AF) in the general Chinese population is $0.77 \%$. What is more, it affects more than $12.2 \%$ people over 85 years old. AF is associated with higher risk of ischemic stroke and is responsible for greater mortality and morbidity. ${ }^{3}$ Evidence from a series of trials has shown that oral anticoagulant therapy (OAT) reduces stroke and improves other outcomes in patients with NVAF. ${ }^{4}$ Accordingly, in recent years, a number of international guidelines have recommended OAT for patients 
with NVAF. ${ }^{5,6}$ However, previous studies have shown the low rate of receiving OAT in NVAF patients in the People's Republic of China several years ago. ${ }^{1}$ As a result, this study is designed to investigate antithrombotic therapy status in elderly patients with NVAF in our hospital between January 2012 and December 2013.

\section{Methods}

\section{Study population}

This was an observational study based on chart review from an electronic clinical information system in our hospital. Older patients ( $\geq 60$ years) with NVAF were eligible for this study. Diagnosis of AF is based on electrocardiography (ECG) (12-lead ECG), or 24-hour Holter. Demographics, other medical diagnoses, antithrombotic or antiplatelet therapy, and laboratory data were also collected. Exclusion criteria included any one of the following conditions: valvular AF, rheumatic mitral stenosis, a mechanical or bioprosthetic heart valve, mitral valve repair, and death in hospital. Data was consecutively collected from the patients discharged between January 2012 and December 2013. $\mathrm{CHA}_{2} \mathrm{DS}_{2}$-VASc score (cardiac failure or dysfunction, hypertension, age $\geq 75$ [doubled], diabetes, stroke/transient ischemic attack [TIA] [doubled], vascular disease, age 65-74, and sex category $[$ female $])^{5}$ was used for stroke risk stratification.

\section{Statistical analysis}

Data analysis was performed with SPSS, version 19.0 (IBM Corporation, Armonk, NY, USA). Continuous variables were reported as mean \pm standard deviation or as median (interquartile range). Among-group comparisons of continuous variables were analyzed with nonparametric test (Kruskal-Wallis test). Categorical variables were reported as frequencies (percentages). Among-group comparisons of categorical variables were analyzed with chi-square test. All $P$-values were two sided, and a $P$-value of $<0.05$ was considered to be defined as statistically significant.

\section{Results}

\section{Patient characteristics}

Between January 2012 and December 2013, a total of 1,000 elderly NVAF patients were consecutively enrolled, and 128 elderly AF patients were excluded. Demographic characteristics and risk factors of stroke are presented in Table 1.

\section{Use of antithrombotics}

Among the 1,000 patients, 291 patients (29.1\%) received OAT, including 278 patients $(27.8 \%)$ prescribed warfarin
Table I Patient characteristics according to $\mathrm{CHA}_{2} \mathrm{DS}_{2}-\mathrm{VASc}$ risk score

\begin{tabular}{|c|c|}
\hline Characteristic & Total sample $(n=I, 000)$ \\
\hline Mean age, years $( \pm S D)$ & $75.3 \pm 8.0$ \\
\hline \multicolumn{2}{|l|}{ Age } \\
\hline$<65$ years, $\mathrm{n}(\%)$ & III (II.I) \\
\hline 65-74 years, n (\%) & $342(34.2)$ \\
\hline$\geq 75$ years, $\mathrm{n}(\%)$ & $547(54.7)$ \\
\hline Female, $\mathrm{n}(\%)$ & $427(42.7)$ \\
\hline \multicolumn{2}{|l|}{ Type of AF } \\
\hline Paroxysmal, n (\%) & $394(39.4)$ \\
\hline Non-paroxysmal, n (\%) & $606(60.6)$ \\
\hline \multicolumn{2}{|l|}{ Past medical history } \\
\hline Hypertension, n (\%) & $7 \mid 5(7 \mid .5)$ \\
\hline CHF, n (\%) & $316(31.6)$ \\
\hline CAD, n (\%) & $418(41.8)$ \\
\hline Diabetes, n (\%) & $336(33.6)$ \\
\hline Stroke or TIA, $n(\%)$ & $319(31.9)$ \\
\hline Vascular disease, $\mathrm{n}(\%)$ & $254(25.4)$ \\
\hline \multicolumn{2}{|l|}{$\mathrm{CHA}_{2} \mathrm{DS}_{2}-\mathrm{VASc}$ risk score } \\
\hline Median score (interquartile range) & $4(3-5)$ \\
\hline Low risk (score 0), n (\%) & $12(1.2)$ \\
\hline Intermediate risk (score I), n (\%) & $65(6.5)$ \\
\hline High risk (score $\geq 2$ ), n (\%) & $923(92.3)$ \\
\hline
\end{tabular}

Notes: Non-paroxysmal AF refers to persistent and permanent AF. $\mathrm{CHA}_{2} \mathrm{DS}_{2}-\mathrm{VASc}$ score $=$ one point each for the presence of congestive heart failure, hypertension, diabetes mellitus, vascular disease, age 65-74 years, and female; and two points for age 75 years or older and a history of stroke or TIA.

Abbreviations: AF, atrial fibrillation; $C A D$, coronary artery disease; $C H F$, congestive heart failure; SD, standard deviation; TIA, transient ischemic attack.

and the rest (1.3\%) took novel oral anticoagulants, 395 patients $(39.5 \%)$ took antiplatelet drugs including aspirin and/or clopidogrel, and 314 patients (31.4\%) were not on oral anticoagulants or antiplatelet drugs.

\section{Use of OAT according to $\mathrm{CHA}_{2} \mathrm{DS}_{2}-\mathrm{VASc}$ score}

Based on the $\mathrm{CHA}_{2} \mathrm{DS}_{2}-\mathrm{VASc}$ score, the OAT rates were $25.0 \%$, $24.6 \%$, and $29.5 \%$, respectively, in patients with the score of 0,1 , and $\geq 2$. The $\mathrm{CHA}_{2} \mathrm{DS}_{2}-\mathrm{VASc}$ score was not significantly associated with the rate of receiving $\operatorname{OAT}(P=0.403)$ (Figure 1). What is more, the proportion of patients receiving antithrombotic therapy in the score $\geq 1$ and score $\geq 2$ groups were $68.9 \%$ (681/988) and 70.2\% (648/923), respectively. The rate of OAT in the score $\geq 1$ group reached $29.1 \%$ (288/988).

\section{Use of OAT in high-risk stroke patients $\left(\mathrm{CHA}_{2} \mathrm{DS}_{2}\right.$-VASc score $\geq 2$ )}

The use of OAT among high-risk stroke patients ie, in the $\mathrm{CHA}_{2} \mathrm{DS}_{2}-\mathrm{VASc}$ score $\geq 2(\mathrm{n}=923)$ cohort is shown in Table 2. There were more patients with persistent or permanent AF receiving OAT than patients with paroxysmal AF $(P<0.001)$. The patients aged between 60 and 74 years 


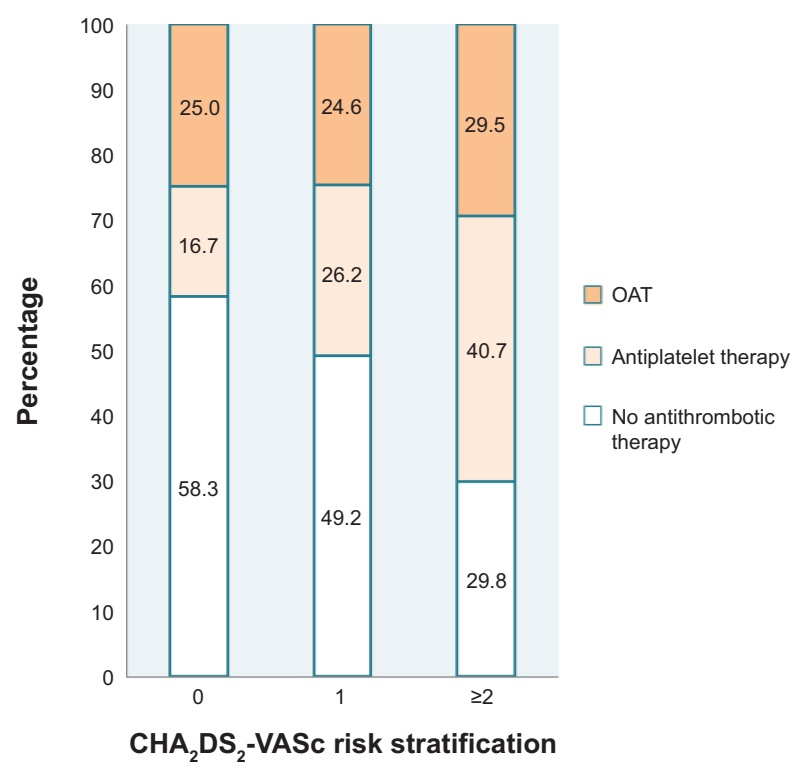

Figure I Prescription rate of antithrombotics according to $\mathrm{CHA}_{2} \mathrm{DS}_{2}-\mathrm{VASc}$ risk stratification.

Notes: $\mathrm{CHA}_{2} \mathrm{DS}_{2}$-VASc score = one point each for the presence of congestive heart failure, hypertension, diabetes mellitus, vascular disease, age 65-74 years, and female; two points for age 75 years or older and a history of stroke or transient ischemic attack.

Abbreviation: OAT, oral anticoagulant therapy.

used more OAT than patients aged $\geq 75$ years $(P=0.003)$. Patients without coronary artery diseases were more likely to receive OAT than patients with coronary artery disease $(P=0.003)$. The sex and history of stroke or TIA had no effect on use of OAT.

Table 2 Use of OAT in high-risk stroke patients $\left(\mathrm{CHA}_{2} \mathrm{DS}_{2}-\right.$ VASc score $\geq 2$ )

\begin{tabular}{|c|c|c|c|c|}
\hline & $\begin{array}{l}\text { Sample } \\
\text { size } n\end{array}$ & $\begin{array}{l}\text { OAT } \\
\text { n (\%) }\end{array}$ & $\chi^{2}$ & $P$-value \\
\hline \multicolumn{5}{|l|}{ Type of AF } \\
\hline Paroxysmal & 354 & $69(19.5)$ & 27.504 & $<0.001$ \\
\hline Persistent and permanent & 569 & $203(35.7)$ & & \\
\hline \multicolumn{5}{|l|}{ Age } \\
\hline$<75$ years & 376 & |3| (34.8) & 8.807 & 0.003 \\
\hline$\geq 75$ years & 547 & I4I (25.8) & & \\
\hline \multicolumn{5}{|l|}{ Sex } \\
\hline Male & 503 & $155(30.8)$ & 0.964 & 0.326 \\
\hline Female & 420 & $117(27.9)$ & & \\
\hline \multicolumn{5}{|l|}{ CAD } \\
\hline Yes & 402 & $98(24.4)$ & 8.881 & 0.003 \\
\hline No & 521 & $174(33.4)$ & & \\
\hline \multicolumn{5}{|l|}{ Stroke or TIA } \\
\hline Yes & 319 & $92(28.8)$ & 0.093 & 0.761 \\
\hline No & 604 & I $80(29.8)$ & & \\
\hline
\end{tabular}

Notes: $\mathrm{CHA}_{2} \mathrm{DS}_{2}-\mathrm{VASc}$ score $=$ one point each for the presence of congestive heart failure, hypertension, diabetes mellitus, vascular disease, age 65-74 years, and female; two points for age 75 years or older and a history of stroke or TIA. A $P$-value of $<0.05$ was considered to be statistically significant.

Abbreviations: AF, atrial fibrillation; CAD, coronary artery disease; OAT, oral anticoagulant therapy; TIA, transient ischemic attack.

\section{Discussion}

The clinical practice guidelines strongly recommend OAT for NVAF patients. ${ }^{5,6}$ However, it was observed that various antithrombotics such as oral anticoagulants and antiplatelet drugs were used in elderly AF patients, whose mean age was 75 years old. Although OAT rates in domestic elderly NVAF patients was higher than previously published survey data, which range from $5.7 \%$ to $14.5 \%,{ }^{7,8}$ OAT were underused in older patients with NVAF (29.1\%), particularly in those with high risk of stroke (29.5\%). Therefore, treatment prescription still deviated largely from guideline recommendations based on $\mathrm{CHA}_{2} \mathrm{DS}_{2}$-VASc score. When compared with European countries, the underuse of OAT in elderly AF patients was also remarkable. Lip et $\mathrm{al}^{9}$ reported that in European real-world clinical practice, a total of $95.6 \%$ NVAF patients with $\mathrm{CHA}_{2} \mathrm{DS}_{2}-\mathrm{VASc}$ score $\geq 1$ received antithrombotic therapy, among which $80.5 \%$ received $\mathrm{OAT}$, and the proportion of OAT prescriptions in those with score $\geq 2$ was $83.7 \%$. We also found that in our study, three patients with $\mathrm{AF}$ and $\mathrm{CHA}_{2} \mathrm{DS}_{2}-\mathrm{VASc}=0$ took short-term anticoagulation, for they received radio-frequency catheter ablation during hospitalizing, in order to prevent secondary thrombosis after the treatment. However, the total number of patients with $\mathrm{AF}$ and $\mathrm{CHA}_{2} \mathrm{DS}_{2}-\mathrm{VASc}$ score of 0 was few $(\mathrm{n}=12)$, thus leading to the relatively high OAT rate $(25.0 \%$ [3/12]) in this population. As a result, no significant difference was observed in the OAT rate between patients with $\mathrm{CHA}_{2} \mathrm{DS}_{2}$-VASc score of 0 and those with score of 1 and $\geq 2$. Otherwise, we noticed that OAT rate was between $20 \%$ and $30 \%$ in both $\mathrm{CHA}_{2} \mathrm{DS}_{2}-\mathrm{VASc}$ score $=1$ and $\geq 2$ patients, not increased significantly with the increase of the score; and we found that antiplatelet therapy rate was $16.7 \%$ in the score $=0$ group and $40.7 \%$ in the score $\geq 2$ group. Both of which weren't consistent with the antithrombotic therapy strategies recommended by AF guidelines, ${ }^{5,6}$ and indicated unreasonable application of antithrombotic therapy. Several possible reasons might explain the inconsistency in our study: 1) some clinical doctors might have insufficient understanding of stroke risk caused by NVAF and be unfamiliar with $\mathrm{CHA}_{2} \mathrm{DS}_{2}$-VASc score and AF guidelines about antithrombotic treatment, so that they gave antiplatelet therapy to patients with the score of 0 and 2;2) patients with NVAF would be more inclined to choose antiplatelet therapy rather than OAT, as they were supposed that the former was safer, more convenient or cheaper; 3 ) a considerable number of doctors and patients were worried about bleeding risk, especially intracerebral hemorrhage caused by OAT, mainly by warfarin. 
Through further analysis, we learned that patients with advanced age were less likely to be prescribed OAT despite high stroke risk, especially in patients older than 75 years. Partington et $\mathrm{al}^{10}$ also found that aging was the strongest predictor for warfarin non-use. Actually, in trials considering the elderly population, OAT was associated with significant reduction in thromboembolism occurrence, as well as lower major bleeding risk. ${ }^{11,12}$ As a consequence, we should enhance the rate of OAT in elderly NVAF patients, especially in patients over 75 years.

We found OAT was also less likely to be used in paroxysmal AF patients (19.5\%), even if a high risk of thromboembolism remained in those patients. This situation was similar to the study outcomes of Friberg et al and Hohnloser et al. ${ }^{13,14}$ Indeed, what really determines stroke risk depends on various elements such as hypertension and diabetes, rather than $\mathrm{AF}$ pattern. So it is emphasized in guidelines that in presence of stroke risk factors, OAT should be prescribed regardless of clinical AF type (paroxysmal, persistent, or permanent). ${ }^{6}$

Previous stroke or TIA increases the risk of stroke recurrence, and usually leads to the worst prognosis in $\mathrm{AF}$ patients. ${ }^{3}$ Thus, in the $\mathrm{CHA}_{2} \mathrm{DS}_{2}$-VASc score, the highest value was given to previous stroke or TIA. Guidelines recommend OAT to be the preferred treatment option for AF patients with a history of stroke or TIA. ${ }^{6}$ However, in this study, we found that the prevalence of stroke or TIA in elderly AF patients has reached $31.9 \%$, while less than $30 \%$ of those patients received OAT, which meant OAT was critically insufficient in this group.

Comorbidity of vascular disease also independently increases the risk of stroke in AF patients. ${ }^{15}$ For one thing, in AF patients with stable vascular disease, OAT is the optimal treatment option. What is more, combination therapy (OAT plus antiplatelets) not only reduces the occurrence rate of thromboembolism, but also substantially increases the risk of major bleeding. ${ }^{5}$ For another thing, situation in AF patients presenting acute coronary syndrome and/or stenting might be much more complicated. The 2012 ESC Atrial Fibrillation Guidelines recommended triple therapy (OAT plus dual antiplatelet therapy) at the early stage, and followed by OAT plus single antiplatelet therapy, then OAT alone. ${ }^{5}$ However, triple therapy is usually associated with high bleeding risk. ${ }^{16}$ Dewilde et $\mathrm{al}^{17}$ found that in patients undergoing percutaneous coronary intervention, coadministration of clopidogrel without aspirin was associated with significant reduction in bleeding complications when compared with dual antiplatelet therapy. Also, no increase in the occurrence rate of thrombotic events was observed. Therefore, the 2014 AHA/ACC/
HRS Atrial Fibrillation Guideline suggests that following coronary revascularization in patients with $\mathrm{CHA}_{2} \mathrm{DS}_{2}-\mathrm{VASc}$ score of $\geq 2$, it may be reasonable to use clopidogrel concurrently with OAT. ${ }^{6}$ In addition, we observed that compared with those elderly patients without coronary disease, elderly AF patients complicated with coronary disease were more likely to take antiplatelet therapy than OAT, so new strategies should be considered for optimizing the use of OAT in this population.

Limitations of this study were as follows: 1) it is a single medical center survey, 2) the sample size was relatively small, and 3) the quality of OAT use was not studied. Patients on OAT might not get therapeutic level of international normalized ratio. So it is possible that the current situation of anticoagulant therapy in elderly AF patients nationwide may not be fully reflected. As a result, further multicenter and larger-scale studies are required to show the status of antithrombotic therapy in elderly AF patients. Furthermore, there were no data considering quality control of anticoagulation. Last but not least, we did not have detailed data on outcomes, which will be illustrated by the ongoing follow-up phase of our study.

In conclusion, our single medical center survey provides contemporary data on oral anticoagulation prescription in elderly AF patients. Oral anticoagulation (mostly vitamin K antagonist administration) has improved in contrast with situations several years ago. Nevertheless, under-treatment with OAT and an inclination to use antiplatelet drugs are still common in elderly patients with NVAF.

\section{Acknowledgments}

This work was supported by the National Science and Technology Support Program, whose topic is Translational Medicine Research of Treatment Risk and Strategy in the Elderly Population (2012BAI37B05). The sponsors did not have a role in the design or conduct of this study, the analysis of data, or preparation of the manuscript. We thank the participants and all of the staff involved in this study.

\section{Disclosure}

The authors have no conflicts of interest to report.

\section{References}

1. Zhou ZQ, Hu DY. An epidemiological study on the prevalence of atrial fibrillation in the Chinese population of mainland China. J Epidemiol. 2008;18(5):209-216.

2. Go AS, Hylek EM, Phillips KA, et al. Prevalence of diagnosed atrial fibrillation in adults: national implications for rhythm management and stroke prevention: the AnTicoagulation and Risk Factors in Atrial Fibrillation (ATRIA) Study. JAMA. 2001;285(18):2370-2375. 
3. Marini C, De Santis F, Sacco S, et al. Contribution of atrial fibrillation to incidence and outcome of ischemic stroke: results from a populationbased study. Stroke. 2005;36(6):1115-1119.

4. Hart RG, Pearce LA, Aguilar MI. Meta-analysis: antithrombotic therapy to prevent stroke in patients who have nonvalvular atrial fibrillation. Ann Intern Med. 2007;146(12):857-867.

5. Camm AJ, Lip GY, De Caterina R, et al. 2012 focused update of the ESC Guidelines for the management of atrial fibrillation: an update of the 2010 ESC Guidelines for the management of atrial fibrillation. Developed with the special contribution of the European Heart Rhythm Association. Eur Heart J. 2012;33(21):2719-2747.

6. January CT, Wann LS, Alpert JS, et al. 2014 AHA/ACC/HRS Guideline for the Management of Patients with Atrial Fibrillation: executive summary: a report of the American College of Cardiology/American Heart Association Task Force on Practice Guidelines and the Heart Rhythm Society. J Am Coll Cardiol. Epub 2014 Mar 28.

7. Qi ZG, Wang HZ, Gao Y. Antithrombotic therapy in 875 elderly patients with atrial fibrillation. Chinese Journal of Geriatric Heart Brain and Vessel Diseases. 2011;9:805-807. Chinese.

8. Guo YT, Wu Q, Zhang L, et al. Antithrombotic therapy in very elderly patients with atrial fibrillation: is it enough to assess thromboembolic risk? Clin Interv Aging. 2010;5(25):157-162.

9. Lip GY, Laroche C, Dan GA, et al. 'Real-world' antithrombotic treatment in atrial fibrillation: the EORP-AF pilot survey. Am J Med. 2014;127(6):519-529.e1.

10. Partington SL, Abid S, Teo K, Oczkowski W, O’Donnell MJ. Preadmission warfarin use in patients with acute ischemic stroke and atrial fibrillation: The appropriate use and barriers to oral anticoagulant therapy. Thromb Res. 2007;120(5):663-669.
11. Poli D, Antonucci E, Testa S, Tosetto A, Ageno W, Palareti G. Bleeding risk in very old patients on vitamin $\mathrm{K}$ antagonist treatment: results of a prospective collaborative study on elderly patients followed by Italian Centres for Anticoagulation. Circulation. 2011;124(7):824-829.

12. Tincani $\mathrm{E}$, Baldini $\mathrm{P}$, Crowther $\mathrm{MA}$, et al. Bleeding rates in patients older than 90 years of age on vitamin $\mathrm{K}$ antagonist therapy for nonvalvular atrial fibrillation. Blood Coagul Fibrinolysis. 2009;20(1):47-51.

13. Friberg L, Hammar N, Rosenqvist M. Stroke in paroxysmal atrial fibrillation: report from the Stockholm Cohort of Atrial Fibrillation. Eur Heart J. 2010;31(8):967-975.

14. Hohnloser SH, Pajitnev D, Pogue J, et al. Incidence of stroke in paroxysmal versus sustained atrial fibrillation in patients taking oral anticoagulation or combined antiplatelet therapy: an ACTIVE W Substudy. $J$ Am Coll Cardiol. 2007;50(22):2156-2161.

15. Olesen JB, Lip GY, Lane DA, et al. Vascular disease and stroke risk in atrial fibrillation: a nationwide cohort study. $\mathrm{Am} \mathrm{J} \mathrm{Med}$. 2012;125(8):813-826.

16. Hansen ML, Sorensen R, Clausen MT, et al. Risk of bleeding with single, dual, or triple therapy with warfarin, aspirin, and clopidogrel in patients with atrial fibrillation. Arch Intern Med. 2010;170(16):1433-1441.

17. Dewilde WJ, Oirbans T, Verheugt FW, et al. Use of clopidogrel with or without aspirin in patients taking oral anticoagulant therapy and undergoing percutaneous coronary intervention: an open-label, randomised, controlled trial. Lancet. 2013;381(9872):1107-1115.
Clinical Interventions in Aging

\section{Publish your work in this journal}

Clinical Interventions in Aging is an international, peer-reviewed journa focusing on evidence-based reports on the value or lack thereof of treatments intended to prevent or delay the onset of maladaptive correlates of aging in human beings. This journal is indexed on PubMed Central, MedLine,

\section{Dovepress}

CAS, Scopus and the Elsevier Bibliographic databases. The manuscript management system is completely online and includes a very quick and fair peer-review system, which is all easy to use. Visit http://www.dovepress. com/testimonials.php to read real quotes from published authors. 